\title{
FASKEN MARTINEAU
}

For information contact:

\section{Sally Woods}

Director, Professional Personnel

4168683468

sallywoods@tor.fasken.com

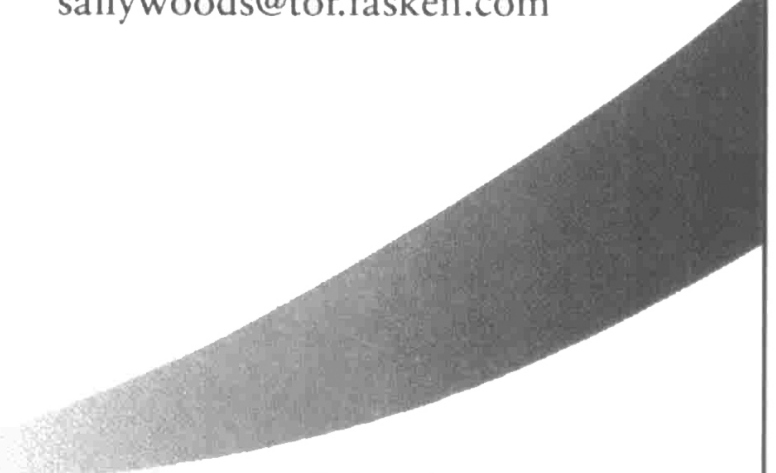

Fasken Martineau DuMoulin LLP

Barristers and Solicitors

Patent and Trade-mark Agents 
